\title{
Are Meridian Tapping Point and Breathing Exercise Techniques Effective to Reduce Stress and Vital Signs in Haemodialysis Patients?
}

\author{
Anita Shinta Kusuma ${ }^{1 *}$, Berlian Nurtyashesti Kusumadewi ${ }^{1}$ \\ ${ }^{1}$ Ngesti Waluyo Nursing Academy, Temanggung 56254, Indonesia \\ *Corresponding author. Email: shinta.kusuma75@gmail.com
}

\begin{abstract}
Most haemodialysis patients experience moderate to high level of anxiety and stress. This requires coping skills and techniques that can be used to effectively reduce stress level, and increase the participation of hospitals to improve service quality. This study aims to determine the impact of Meridian Tapping Point combined with Breathing Exercise Technique to the stress level, blood pressure \& pulse rate of haemodialysis patients at Christian Hospital Ngesti Waluyo Parakan. Design: A quasi experimental one group pre-test-posttest design was conducted. The study was conducted on June 26 to July 15, 2019, with total respondent 46 haemodialysis patients. With variables stress, blood pressure, pulse rate. Data were analysed using paired sample t-test. Result: The results showed that a decrease in PSS score, blood pressure and pulse in the post test. The difference of score between pre-test and post-test was $0.000(\mathrm{p}<0.05)$. Meanwhile, the difference of systolic blood pressure between pre and post-test was $0.001(\mathrm{p}<0.05)$, for diastolic, the difference of score was $0.03(\mathrm{p}<0.05)$, and for pulse the difference score was $0.043(\mathrm{p}<0.05)$. Thus, there is a significant difference in the stress level, blood pressure and pulse rate before and after the intervention.

Keywords: meridian tapping point, breathing exercise techniques, haemodialysis
\end{abstract}

\section{INTRODUCTION}

One of the standards in the Hospital Accreditation National Standards (SNARS) [1], which is communication and education management standards (MKE 6), explains that hospitals must provide education to support patient and family participation in the care process. Education is focused on the specific knowledge and skills that is needed to participate in the care process and continue patient care at home. The hospital develops/incorporates education into the care process according to the type of service provided. Education is planned and provided to ensure that every patient gets education according to their needs. The educational process is carried out with appropriate methods based on the needs of the patient, and the material can be easily understood by the patient and family. Based on the 2016 Indonesian Renal Registry (IRR), 98\% of patients with kidney failure undergo haemodialysis (HD) therapy and $2 \%$ undergo Peritoneal Dialysis (PD) therapy. The number of haemodialysis patients both new and active patients from 2007 to 2016 has increased [2]. The result from preliminary studies in HD patients, HD patients experience have moderate to high levels of stress. The main cause of the stress is thinking about the disease.

Stress represents any effect that seriously threatens homeostasis [3]. Stress is a physical response [4]. When stressed, the body thinks that it is under attack and goes into 'fight or flight' mode, releasing a mixture of hormones and complex chemicals substances such as adrenaline, cortisol, and nor- epinephrine. This event causes reactions, such as a faster heartbeat and constricts blood vessels. Stress increases peripheral vascular resistance, cardiac output, also stimulates sympathetic nervous system activity.

Complementary and Alternative Medicines have played a significant role in human health care [5]. The manual stimulation of acupuncture points has been combined with components of cognitive and exposure therapies into a clinical and self-help approach known as Emotional Freedom Techniques (EFT) [6]. Various stresses relieving technique like tapping meridian point and breathing exercise are considered as technique that can decrease stress, blood pressure and pulse rate haemodialysis patients. This technique can support balance in the body's homeostatic functions and as a modality therapy to normalize the function of the autonomic nervous system to support the body's immunity. In the hospital where the study is conducted, there is no educational service for patients to measure and reduce their stress levels, neither to do tapping as a strategy to reduce the stress level. For this reason, this is part of the efforts of Ngesti Waluyo Hospital to improve quality of service.

\section{METHOD}

This research aimed to determine the impact of Meridian Tapping Point combined with breathing exercise technique and verbal persuasion to the stress level, blood pressure and pulse of haemodialysis patients. The hypotheses of the study were: There is a significant difference in the stress level, blood pressure and pulse rate before and after the intervention. Meridian Tapping Point combined with 
answers questions that are relevant to how the technique should be carried out. To complement the instructional, the researcher developed a teaching leaflet to reinforce the participants' knowledge and skills on this technique of meridian tapping points. The exercise technique to control your breathing was developed for their respiratory rehabilitation education and exercise program [7].

\subsection{Data Collection}

The data collection during June 26 to July 15,2019 . In this study, the researcher utilized a questionnaire Perceived Stress Scale (PSS) with permission from the author to measure the level of stress level. The bio-physiologic instruments utilized for vital signs were the following: aneroid blood pressure apparatus, stethoscope and a wristwatch with a minute hand.

The researcher measured the stress level using the Perceived Stress Scale (PSS) that was created by [8]. This questioner has 10 questions with 5 answering intervals $0-4$, consisted of 0 (never) to 4 (very often). PSS scores were obtained by reversing the scores on the 4 positive items (Items $4,5,7 \& 8$ ), e.g., $0=4,1=3,2=2,3=1,4=0$ then summing across all 10 items to produce a range 0 to 40 , with higher scores indicating higher levels for stress. Interpretation of PSS was determined as follows: Scores ranging from $0-13$ will be considered low stress, $14-26$ will be considered moderate stress, and 27-40 will be considered high perceived stress.

\subsection{Data Analysis}

The univariate analysis was conducted to determine of respondents' characteristics; whereas, the bivariate analysis was performed to determine the differences variables between pre-test and post-test. Paired sample t-test was performed to know the difference change in PSS score, blood pressure and pulse between pre-test and post-test. The researcher used Statistical Product and Service Solution (SPSS) Version 16.

\section{RESULTS AND DISCUSSION}

All of the study respondents completed the research process, so that all of the respondents were analysed and none was excluded from the analysis in Figure 1. 


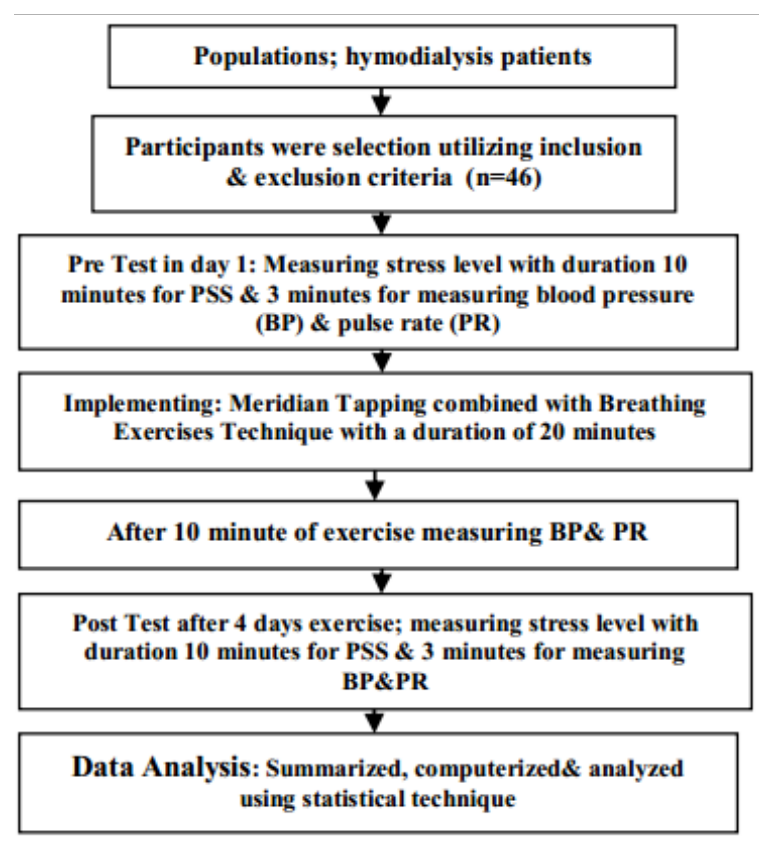

Figure 1 Research process flowchart

The characteristics of the study sample including gender and the length of haemodialysis are summarized in Table 1.

Table 1 Characteristics of respondents

\begin{tabular}{|lc|}
\hline \multicolumn{1}{|c|}{ Characteristics } & n (\%) \\
\hline Gender & \\
\hline Male & $20(43.5)$ \\
Female & $26(56.5)$ \\
\hline Length of haemodialysis & \\
\hline $1-12$ month & $20(43.48)$ \\
$13-24$ month & $23(50)$ \\
$25-36$ month & - \\
$37-48$ month & $1(2.17)$ \\
$49-60$ month & $1(2.17)$ \\
$\geq 60$ month & $1(2.17)$ \\
\hline
\end{tabular}

Based on Table 1, most respondents were female and for length of haemodialysis time of 13-24 months. Table 2 represents the statistical test results of PSS, blood pressure and pulse, which were measured before the intervention (pre-test) and after intervention (post-test). PSS, blood pressure and pulse rate were normally distributed so the paired sample t-test was used.

Table 2 Difference of PSS, blood pressure and pulse rate pre-test and post-test between male and female

\begin{tabular}{|c|c|c|c|c|c|c|c|}
\hline & \multicolumn{3}{|c|}{ Male } & \multicolumn{3}{|c|}{ Female } & \multirow[t]{2}{*}{ p-value } \\
\hline & $\mathbf{n}$ & $\begin{array}{l}\text { Median } \\
\text { (min-max) }\end{array}$ & $\begin{array}{l}\text { Mean } \\
\pm \text { SD }\end{array}$ & $\mathbf{n}$ & $\begin{array}{c}\text { Median } \\
\text { (min-max) }\end{array}$ & $\begin{array}{l}\text { Mean } \\
\pm \text { SD }\end{array}$ & \\
\hline \multicolumn{8}{|c|}{ PRE-TEST } \\
\hline PSS & 20 & $\begin{array}{c}13 \\
(6-27)\end{array}$ & $\begin{array}{l}13.85 \\
\pm 4.90 \\
\end{array}$ & 26 & $\begin{array}{c}18.5 \\
(8-26)\end{array}$ & $\begin{array}{l}17.42 \\
\pm 4.75 \\
\end{array}$ & .012 \\
\hline \multicolumn{8}{|l|}{ BP } \\
\hline Systolic & 20 & $\begin{array}{c}162 \\
(127-218)\end{array}$ & $\begin{array}{r}163.2 \\
\pm 24.84\end{array}$ & 26 & $\begin{array}{c}182 \\
(114-223)\end{array}$ & $\begin{array}{l}175.58 \\
(26.91)\end{array}$ & .456 \\
\hline Diastolic & 20 & $\begin{array}{c}94.5 \\
(66-122)\end{array}$ & $\begin{array}{c}91.25 \\
\pm 14.18\end{array}$ & 26 & $\begin{array}{c}98 \\
(69-128)\end{array}$ & $\begin{array}{r}97.27 \\
\pm 14.76\end{array}$ & .212 \\
\hline Pulse & 20 & $\begin{array}{c}88 \\
(60-117) \\
\end{array}$ & $\begin{array}{l}86.95 \\
\pm 13.77 \\
\end{array}$ & 26 & $\begin{array}{c}87 \\
(73-115) \\
\end{array}$ & $\begin{array}{c}88.87 \\
(73-115) \\
\end{array}$ & .963 \\
\hline \multicolumn{8}{|c|}{ POST-TEST } \\
\hline PSS & 20 & $\begin{array}{c}11 \\
(2-24)\end{array}$ & $\begin{array}{l}10.80 \\
\pm 4.18\end{array}$ & 26 & $\begin{array}{c}14 \\
(6-21)\end{array}$ & $\begin{array}{l}13.97 \\
\pm 4.22\end{array}$ & .033 \\
\hline \multicolumn{8}{|l|}{$\overline{\mathrm{BP}}$} \\
\hline Systolic & 20 & $\begin{array}{c}152.5 \\
(116-208)\end{array}$ & $\begin{array}{l}155.75 \\
\pm 24.92\end{array}$ & 26 & $\begin{array}{c}169.5 \\
(117-210)\end{array}$ & $\begin{array}{l}166.19 \\
\pm 23.05\end{array}$ & .318 \\
\hline Diastolic & 20 & $\begin{array}{c}90 \\
(66-119)\end{array}$ & $\begin{array}{l}89.05 \\
\pm 14.56\end{array}$ & 26 & $\begin{array}{c}93 \\
(72-121)\end{array}$ & $\begin{array}{c}93.58 \\
\pm 12.97\end{array}$ & .259 \\
\hline Pulse & 20 & $\begin{array}{c}86 \\
(61-114)\end{array}$ & $\begin{array}{c}85.1 \\
\pm 14.24\end{array}$ & 26 & $\begin{array}{c}87 \\
(68-100)\end{array}$ & $\begin{array}{l}86.42 \\
\pm 8.11\end{array}$ & .909 \\
\hline
\end{tabular}


Table reveals that there was significant difference in PSS variable in pre-test between male and female $(p<0.05)$, for blood pressure and pulse rate variables there was no significant difference between male and female $(\mathrm{p}>0.05)$. While for post-test the result showed there was significant difference in PSS variable between male and female $(p<$ 0.05 ) and for blood pressure, pulse rate there was no significant difference between male and female $(\mathrm{p}>0.05)$. Whereas the result of PSS and blood pressure, pulse rate showed there are decreasing median a well as minimum and maximum scores in post-test both of male and female, except the median score in pulse rate in male group has the same result. Many studies suggest that women have more stress than men [9]. Presently, perhaps the best interpretation of the research on sex and stress is that women may experience certain stressors more often than men (e.g., work/family conflict), men and women may react differently to certain types of stressors.

Table 1 showed respondents received haemodialysis for various length of time. The researcher took respondents from the length of haemodialysis time of 1-12 months and 13-24 months, that have the greatest number of subjects. Table 3 represents the statistical test results of PSS, blood pressure and pulse rate which were measured before the intervention and after intervention. PSS, blood pressure and pulse rate were normally distributed so the paired sample ttest was used.

Table 3 Difference of PSS, blood pressure and pulse rate pre-test and post-test between male and female

\begin{tabular}{|c|c|c|c|c|c|c|c|}
\hline & \multicolumn{3}{|c|}{ 1-12 months } & \multicolumn{3}{|c|}{ 13-24 months } & \multirow[t]{2}{*}{ p-value } \\
\hline & $\mathbf{n}$ & $\begin{array}{l}\text { Median } \\
\text { (min-max) }\end{array}$ & $\begin{array}{l}\text { Mean } \\
\pm \text { SD }\end{array}$ & $\mathbf{n}$ & $\underset{\text { (min-max) }}{\text { Median }}$ & $\begin{array}{l}\text { Mean } \\
\pm \text { SD }\end{array}$ & \\
\hline \multicolumn{8}{|c|}{ PRE-TEST } \\
\hline PSS & 20 & $\begin{array}{r}15.5 \\
(6-24)\end{array}$ & $\begin{array}{l}15.1 \\
\pm 4.91\end{array}$ & 23 & $\begin{array}{c}17 \\
(8-27)\end{array}$ & $\begin{array}{l}16.52 \\
\pm 5.19\end{array}$ & .398 \\
\hline \multicolumn{8}{|l|}{ BP } \\
\hline Systolic & 20 & $\begin{array}{c}165 \\
(139-223) \\
\end{array}$ & \begin{tabular}{|c|}
172.6 \\
\pm 24.16 \\
\end{tabular} & 23 & \begin{tabular}{c|}
172 \\
$(114-218)$ \\
\end{tabular} & \begin{tabular}{|l|}
169.56 \\
\pm 28.79 \\
\end{tabular} & .700 \\
\hline Diastolic & 20 & $\begin{array}{c}94.5 \\
(66-128)\end{array}$ & $\begin{array}{c}92.1 \\
\pm 16.01 \\
\end{array}$ & 23 & $\begin{array}{c}97 \\
(71-122)\end{array}$ & $\begin{array}{r}97.96 \\
\pm 13.57 \\
\end{array}$ & .244 \\
\hline Pulse & 20 & $\begin{array}{c}85 \\
(73-115) \\
\end{array}$ & $\begin{array}{c}87 \\
\pm 11.62 \\
\end{array}$ & 23 & $\begin{array}{c}88 \\
(60-117) \\
\end{array}$ & \begin{tabular}{|l|}
88.56 \\
\pm 12.69 \\
\end{tabular} & .691 \\
\hline \multicolumn{8}{|c|}{ POST-TEST } \\
\hline PSS & 20 & $\begin{array}{c}12.5 \\
(2-17)\end{array}$ & $\begin{array}{r}11.75 \\
\pm 3.85\end{array}$ & 23 & $\begin{array}{c}12 \\
(6-24)\end{array}$ & $\begin{array}{l}13.17 \\
\pm 4.73 \\
\end{array}$ & .336 \\
\hline \multicolumn{8}{|l|}{ BP } \\
\hline Systolic & 20 & $\begin{array}{c}161.5 \\
(122-210) \\
\end{array}$ & \begin{tabular}{|l|}
162.95 \\
\pm 24.87 \\
\end{tabular} & 23 & $\begin{array}{c}167 \\
(116-208) \\
\end{array}$ & $\begin{array}{l}162.82 \\
\pm 23.51\end{array}$ & .969 \\
\hline Diastolic & 20 & $\begin{array}{c}93 \\
(66-121)\end{array}$ & \begin{tabular}{|l|}
89.85 \\
\pm 13.86 \\
\end{tabular} & 23 & $\begin{array}{c}92 \\
(70-119)\end{array}$ & \begin{tabular}{|l|}
93.87 \\
\pm 14.07 \\
\end{tabular} & .283 \\
\hline Pulse & 20 & $\begin{array}{c}89.5 \\
(64-100)\end{array}$ & $\begin{array}{l}85.85 \\
\pm 10.91 \\
\end{array}$ & 23 & $\begin{array}{c}85 \\
(61-114)\end{array}$ & \begin{tabular}{|l|}
85.13 \\
\pm 11.76 \\
\end{tabular} & .768 \\
\hline
\end{tabular}

The result showed that there was no significant difference in PSS, blood pressure, and pulse rate variables in pre-test and post-test between the length of haemodialysis 1-12 months and 13-24 months ( $p>0.05)$. Based on the result of PSS and blood pressure, pulse rate showed there are decreasing median a well as minimum and maximum scores in post-test both of group (the length of haemodialysis) except median score in pulse rate group with length of haemodialysis 1-12 months, there is increasing.

Table 4 represents the statistical test results of PSS, blood pressure and pulse rate, which were measured before the intervention (pre-test) and after intervention (post-test). PSS, blood pressure and pulse rate were normally distributed, so the paired sample t-test was used.

Table 4 Difference of PSS, blood pressure and pulse rate between pre-test and post-test

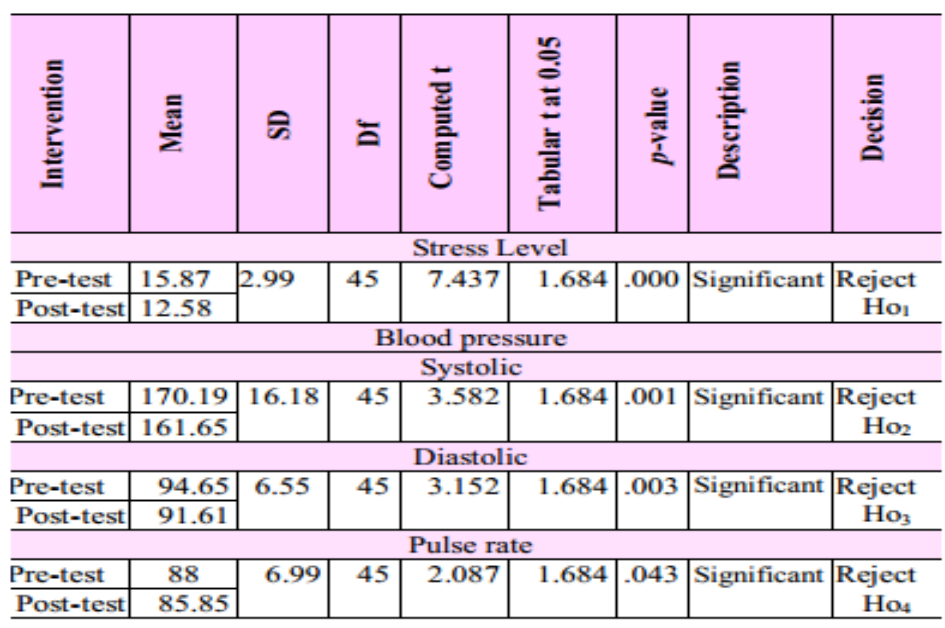


Table 4 showed that there was significant difference in PSS, $\mathrm{BP}$, and pulse rate variables between pre-test and post-test $(\mathrm{p}<0.05)$.

\section{DISCUSSION}

In this research all participants routinely performed haemodialysis 2 times a week. Ngesti Waluyo hospital has 10 machines for haemodialysis, and the hospital is continuously improving the quality of service for patients including in haemodialysis patients. To improve the quality of service in terms of reducing patients' stress, there is various stress relieving techniques that are chosen. The intervention was conducted especially for haemodialysis patients with hypertension, because it is also aimed to find out the impact of the intervention on the blood pressure and pulse rate. In this research, there is a decrease in stress level; the mean score for the stress level in the pre-test is 15.87 (moderate), in the post-test it becomes 12.59 (mild), so there is a decrease in the score of $3.28(20.67 \%)$. The difference is statistically significant, as evidenced by the p-value of less than $0.05(\mathrm{p}=.000)$ (table 4). This study is similar with previous research which evaluated The Effect of EFT on Stress Biochemistry: A Randomized Controlled Trial, the study found that there is The EFT group experienced a significant decrease in cortisol level [10]. The decrease in cortisol levels in the EFT group reflected the observed improvement in psychological distress.

Another result of this study showed that there is a decrease in systolic, diastolic blood pressure and pulse rate. The results are: the mean score for systolic blood pressure in the pre-test $170.20 \mathrm{mmHg}$, in the post-test to $161.65 \mathrm{mmHg}$, so there was a decrease in the score of $8.55 \mathrm{mmHg}(5.02 \%)$; and the variable has significant difference, as evidenced by the p-value of less than $0.05(\mathrm{p}=.001)$ (table 4). While diastolic blood pressure in the pre-test was $94.65 \mathrm{mmHg}$, in the post-test to $91.61 \mathrm{mmHg}$ there was a decrease in the score of $3.04 \mathrm{mmHg}(3.21 \%)$, and the variable has significant difference, as evidenced by the p-value of less than $0.05(\mathrm{p}=.003)$. In the variable of pulse rate, the average pre-test is 88 times per minute, in the post-test is 85.85 times per minute, so there is a score decreased by $2.15(2.44 \%)$. The pulse rate variable is also significantly different, as evidenced by the $\mathrm{p}$ - value of less than $0.05(\mathrm{p}=.043)$. This research finds the positive impact of the intervention on blood pressure supported by Grossman research [11]. He finds that breathing exercise guided by the BIM device for 10 min daily is an effective non-pharmacological modality to reduce BP. Practicing slow deep breathing exercise decreased the systolic and diastolic BP as well as heart rate of patients with essential hypertension [12].

Another finding about the positive impact of the intervention on stress level support that stress can cause a short- term increase in blood pressure, and a relaxation technique and response has been shown to reduce blood pressure in the short term [13]. These results are consistent with this study that various stress relieving techniques can reduce blood pressure, and pulse rates in haemodialysis patients with hypertension. Another study by M. Gowri and Janet.S, they evaluated the effect of deep breathing exercise in hypertensive patients, and the result was significant different before and after intervention [14]. In that research, the mean of systolic blood pressure before intervention was $136.6 \mathrm{mmHg}$ and diastolic was $95.33 \mathrm{mmHg}$, whereas after intervention there is a decreased in the blood pressure: the mean of systolic blood pressure was $126.67 \mathrm{mmHg}$ and diastolic was $87.33 \mathrm{mmHg}$. The finding of this study about the positive effects of tapping meridian points is supported by N. Ortner, Tapping is a set of techniques that utilize the body's energy meridian points and healing power, like acupuncture and acupressure [15].

With this method one can discover important secrets for emotional wholeness and physical relief, creating physical and emotional well-being, and also this method is simple for the haemodialysis patient. Although this study is quantitative in design, the researcher validated these results through subjective data which included testimonials during casual talks with the participants; they verbalized the positive results of stress and blood pressure.

It was also found in this study that there was no significant difference in post-test results between male and female, also between the length of haemodialysis for 1-12 months and 13-24 months. This can be concluded that even though the woman respondent/in the length of haemodialysis for 13-24 months has a higher score in the pre-test but after the intervention is obtained the decrease in the result in the posttest there is no significant difference from the male respondent/in the length of haemodialysis for 1-12 months. So, interventions carried out with the right techniques and put positive things in the mind that are repeated over and over in the mind, and high motivation to get satisfactory results can have the results as expected. Based on the findings above, this intervention also teaches how to modify participant negative feelings so that they can make better judgments and interpretations of their abilities and positive thinking.

\section{CONCLUSION}

The study reveals that Meridian tapping point intervention combined with breathing exercise has an impact on patients' stress level, blood pressure and pulse rate. The research shows that there is a score decrease on Perceived stress scale, blood pressure, and pulse rate; and the difference is statistically significant. To improve the quality of service, it is recommended for nurses to give various stresses relieving technique: e.g. Meridian tapping point combination with breathing exercise for haemodialysis patients, and also encourages positive thinking/feelings will have positive responds and result after interventions.

\section{ACKNOWLEDGMENT}

The authors would like to acknowledge participating haemodialysis patients who were involved in this study. 
[9] Aamodt, M, Industrial/Organizational Psychology an Applied Approach. Belmont, CA: Wadsworth Cengage Learning, 2010.

[10] G. Church, G. Yount, and A. Brooks, "The effect of emotional freedom techniques on stress biochemistry: a randomized controlled trial," US Natl. Libr. Med. Natl. Inst. Health, vol. 200, no. 10, pp. 891-6, 2012.

[11] Grossman, E, Schein, M, Grossman, A, and Zimlichman, R, "Breathing Control Lowers Blood Pressure. Journal of Human Hypertension," US Natl. Libr. Med. Natl. Inst. Health, vol. 15, no. 4, pp. 9-263, 2001.

[12] Mohamed, L, Hanafy, N, and Naby, A, "Effect of Slow Deep Breathing Exercise on Blood Presure and Heart rate among Newly Diagnosed Patients with Essential Hypertension," J. Educ. Pract., vol. 5, no. 4, 2013.

[13] National Center for Complementary and Integrative Health, "Relaxation Techniques for Health," US Dep. Health Hum. Serv., 2016.

[14] M. Gowri and Janet.S, "Effectivness of breathing exercise on Blood Pressure Among Patients with Hypertension. International Journal of Pharma and Bio Sciences," vol. 8, no. 1, pp. 256-260.

[15] N. Ortner. N, "The Tapping Solution: A Revolutionary system for stress-free living," United States: Hay House, 2013. 